\title{
PEQUEÑA EXPLOTACIÓN AGRÍCOLA, REPRODUCCIÓN DE LAS UNIDADES FAMILIARES CAMPESINAS Y MERCADO DE TRABAJO EN LA VITICULTURA MEDITERRÁNEA DEL SIGLO XIX: EL CASO CATALÁN ${ }^{1}$
}

JOSEP COLOMÉ FERRER

Universitat de Barcelona

\section{RESUMEN}

En la Cataluña de los siglos XVIII y XIX, la pequeña propiedad de la tierra jugó un papel determinante en el proceso de especialización vitícola que conocieron diferentes comarcas catalanas. El producto bruto que se obtenía en estas pequeñas propiedades difícilmente podía garantizar la reproducción de las unidades familiares campesinas vinculadas a estas pequeñas superficies de viñedos. Es por ello que en este artículo se analizan las diferentes estrategias seguidas por estas familias a la hora de garantizar su reproducción, tanto como unidades de consumo como de producción.

\section{ABSTRACT}

Small landownership had an outstanding role in determining the process of viticultural specialization that some well-defined territories known as "comarcas" experienced in eighteenth and nineteenth-century Catalonia. The net

${ }^{1}$ Este trabajo se inscribe en el proyecto de investigación «Factores determinantes del desarrollo agrario en Cataluña: recursos naturales, organización del trabajo agrario y cambio tecnológicom (PB96-1157-CO3-02), financiado por la Secretaría de Estado de Universidades e Investigación (DGICYT). Las sucesivas versiones de este artículo se han enriquecido con los comentarios de Ramón Garrabou, Pere Pascual, José Morilla, Jordi Planas, Enric Saguer, James Simpson, Raimon Soler, Carles Sudrià y Francesc Valls, así como de varios evaluadores anónimos. Pese a todo, los errores que puedan detectarse son de mi exclusiva responsabilidad. 
product these small landholdings yielded was not enough to safeguard the reproduction of the peasant family units closely linked to those small areas devoted to vineyards. It is for this reason that this article analyzes the different strategies these families devoloped in order to guarantee their reproduction, either as consumption or production units.

Uno de los rasgos comunes que presentan las comarcas vitícolas catalanas es el elevado grado de concentración de la propiedad de la tierra ${ }^{2}$. $\mathrm{El}$ origen de estas grandes heredades debe enmarcarse en el proceso de diferenciación social que se produjo en el seno de la comunidad campesina, proceso en el que habría resultado determinante la consolidación de grandes explotaciones en enfiteusis, la transmisión de estas explotaciones a través de la figura del bereu y diferentes estrategias matrimoniales encaminadas a ampliar el patrimonio familiar. En el siglo XVIII, estos patrimonios se vieron favorecidos por la inflación que hundió el censo enfitéutico monetarizado ${ }^{3}$ y por la tendencia a disminuir que mostraba la renta señorial, fuertemente afectada por los cambios que se operaron en la estructura productiva y por la intensificación de la resistencia campesina a satisfacer los derechos señoriales ${ }^{4}$.

A mediados del siglo XIX, alrededor de estas grandes heredades detectamos un número considerable de pequeños propietarios, con parcelas que no llegan a alcanzar las 5 hectáreas de tierra, destacando especialmente la propiedad residual (menos de 1 hectárea de tierra) ${ }^{5}$. La consolidación de este importante segmento de pequeños propietarios se halla vinculado al despegue demográfico que experimentó la Cataluña del siglo XVIII ${ }^{6}$. La expansión demográfica facilitó la constitución de pequeñas propiedades a través de dos vías diferentes: por un lado, favoreció la

${ }^{2}$ En la mayor parte de los municipios de la comarca del Alt Penedés, por ejemplo, los grandes propietarios controlaban más del 75 por 100 de la superficie agraria total de cada municipio, llegando en algunos casos, como en los municipios de Gelida y Sant Sadurní d'Anoia, a poseer un porcentaje de tierra superior al 90 por 100 Colomé (1996), p. 242. Algo parecido sucedía en la comarca del Bages, donde los grandes propietarios controlaban entre el 80 y el 90 por 100 de las superficie agraria de los municipios vitícolas Ferrer (1987), p. 235.

${ }^{3}$ Garrabou, Tello y Vicedo (1993), p. 569.

4 Durán (1985). Sobre la evolución de la renta feudal en este periodo ver Caminal et altr. (1978). Respecto a la resistencia campesina a la hora de satisfacer los derechos señoriales, pueden consultarse, entre otros, Torras (1976), Fontana (1980), Cots (1984), Arnabat (1990), Colomé y Valls (1994).

'Colomé (1996), pp. 208-210.

- El incremento demográfico de la Cataluña del xvin fue superior a la media espaniola, beneficiándose de los vacíos provocados por las pestes y crisis de los siglos xJV y xv, la 
expansión de la pequeña propiedad gracias a las características del régimen sucesorio catalán ${ }^{7} \mathrm{y}$, en segundo lugar, el aumento de la población habría comportado su redistribución espacial, tendiendo a concentrarse en los núcleos urbanos ${ }^{8}$. Este proceso favoreció la proliferación de actividades artesanales y probablemente comportó la inversión de dichos artesanos en la adquisición de pequeñas parcelas de tierra. Por otro lado, la multiplicación de pequeñas propiedades se habría visto favorecida por la mayor rentabilidad del viñedo respecto los cultivos herbáceos ${ }^{9}$ y por la demanda de productos vínicos procedente de los mercados de norte de Europa, en el siglo XvII, y del circuito americano a partir del primer tercio del XIX ${ }^{10}$.

En este marco dominado por las grandes heredades y caracterizado por la multiplicación de pequeñas propiedades, el contrato de rabassa morta ${ }^{11}$ jugó un papel dinamizador del proceso de expansión vitícola. En

crisis de mediados del xvi y la guerra de Sucesión. Este crecimiento demográfico reflejaba, también, el cambio estructural que se estaba produciendo en la economía catalana del setecientos. Respecto a las comarcas vitícolas, el crecimiento fue espectacular en el Alt Camp (se pasó de los 9.830 habitantes censados en 1718 a los 25.000 de 1787), y Baix Camp (de 12.421 a 38.312 entre las mismas fechas). El resto del país vitícola muestra tasas de crecimiento inferiores a las señaladas para los casos anteriores. Así, por ejemplo, en el Alt Penedés se pasó de 7.079 habitantes en 1718 a 13.691 en 1787; en el Bages, de 19.123 a 30.721 , y en el Anoia, de 10.062 a 20.139, Nadal (1983), pp. 260 y 266. Sobre este mismo punto, P. Vilar ofrece una información desagregada por municipios. Vilar (1986), pp. 141-181.

7 En el régimen sucesorio catalán, los hijos segundones recibían la legitima, que, según el derecho civil catalán, podía satisfacerse tanto en dinero como con tierras de la heredad, creándose, en este caso, pequeñas propiedades segregadas de la heredad principal.

${ }^{8}$ F. Muñoz destaca para la comarca del Penedés dos períodos diferentes en este proceso de redistribución espacial. En una primera etapa, hasta 1787 , la expansión demográfica favoreció especialmente las localidades más importantes, mientras que en una segunda etapa, comprendida entre 1787 y 1860 , fueron los núcleos urbanos menos poblados los que experimentaron un saldo migratorio positivo Muñoz (1990), pp. 72-73.

${ }^{9}$ Colomé y Valls (1994).

10 Fradera (1987).

1 En las zonas vitícolas catalanas, la explotación de la tierra solia realizarse a través del contrato de rabassa morta. Se trataba de un contrato enfitéutico de naturaleza temporal pero de duración indefinida, que tenía por objeto la cesión de una parcela de tierra al rabassaire para que éste la roturase, plantase de viña y la cultivase a uso y costumbre de buen campesino. El rabassaire disfrutaría del dominio útil de la tierra durante la vida de dos terceras partes de las cepas por él plantadas, a cambio de satisfacer un censo que consistiría en una parte proporcional de la cosecha.

A causa de la conflictividad social que giró alrededor del contrato de rabassa morta, la bibliografia sobre el tema es extensa. Así, a finales del siglo XIX aparecen algunos trabajos, como los de Santamaría (1878 y 1894), que se centran en el tema. En el primer tercio del siglo $\mathrm{xx}$ la producción bibliográfica es más extensa, con trabajos como los de Cañas 
efecto, los grandes propietarios optaron por ceder parte de sus tierras bajo esta fórmula contractual, convirtiendo en productivas zonas hasta el momento no cultivadas (especialmente bosques) y produciéndose una lenta sustitución de cultivos herbáceos por los vitícolas, mejor remunerados. Por otro lado, estos propietarios aumentaban la renta que obtenían de sus tierras gracias a unos censos que, siguiendo las oscilaciones del mercado, se irían revalorizando a lo largo de los años, sin que dichos propietarios tuviesen que asumir los costes de roturación y de producción. Al mismo tiempo, el acceso a tiertas cultivadas bajo la fórmula contractual de la rabassa permitía a un sector de pequeños propietarios constituir una explotación agrícola de más de 6 hectáreas, accediendo a una parte de la renta de la tierra que, como ya indicamos en otro momento ${ }^{12}$, resultaba vital para garantizar la reproducción de dichas unidades familiares campesinas (UFC).

Ante el hecho de que la tierra es un factor limitado, cabe suponer que la expansión demográfica y el avance de la viña que conocieron algunas comarcas catalanas en la segunda mitad del siglo xvirl y la primera del XIX tendieron a acentuar el proceso de diferenciación social en el seno de la comunidad campesina. Producto de este proceso sería la existencia de dos segmentos de población que supuestamente tendrían dificultades para garantizar su reproducción, como unidades de consumo y de producción, a partir de la renta obtenida de sus explotaciones: 1) las UFC que poseían menos de 5 hectáreas, especialmente aquellas que definimos como micropropiedad ${ }^{13}$, y que a pesar de acceder a nuevos viñedos bajo el contrato de rabasssa morta, no trabajaban una superficie de tierra suficiente para garantizar su reproducción, y 2) aquella población que no había podido acceder a la propiedad de la tierra y que tan sólo trabajaba unas pocas hectáreas de tierra bajo el contrato de rabassa morta.

En resumen, Cataluña no sería una excepción en el marco vitícola mediterráneo, y de la misma manera que se ha podido comprobar en el Lan-

y Mañé (1907), Benach (1911), Girona, Boix y Jansana (1923) o Durán y Cañameras (1932). De los trabajos publicados en los últimos años cabe destacar Giralt (1982), Colomé (1990), Moreno (1995) y Valls (1997).

12 Colomé, Saguer y Vicedo (1997), p. 99.

13 En algunos municipios de la comarca del Alt Penedés, por ejemplo, la micropropiedad (menos de 1 ha.) representaba más del 50 por 100 sobre el total de propietarios. Esto es lo que sucedía, por ejemplo, en Les Cabanyes, Font-rubí, Olérdola, Pacs, Sant Pere de Riudebitlles, Sant Quintí de Mediona, Vilobí del Penedés y Vilafranca del Penedés. Colomé (1996), pp. 547-566. 
guedoc Rousillon ${ }^{14}$, el Beaujolais y el Lyonnais ${ }^{15}$, o en los viñedos malagueños ${ }^{16}$, en el caso catalán la pequeña propiedad y la pequeña explotación familiar habrían jugado un papel determinante en el proceso de especialización vitícola. Ante este protagonismo cabe preguntarse por las estrategias seguidas por estas UFC para garantizar su reproducción como unidades de consumo y de producción. Consideramos que el estudio del caso catalán puede ofrecer algunas respuestas a esta cuestión, y por ello en este trabajo se plantea una primera aproximación al análisis de dichas estrategias familiares, suponiendo que las familias campesinas tendían a optimizar el uso del factor trabajo para garantizar su reproducción. De esta forma, la hipótesis de la que parten estas páginas es que el elevado grado de concentración de la propiedad de la tierra que se da en las comarcas vitícolas catalanas dificultaba que un porcentaje nada despreciable de UFC tuviesen garantizada su reproducción con el producto obtenido de las tierras que cultivaban. En este marco, los miembros de dichas UFC tendrían que buscar recursos complementarios a través de las rentas salariales, tanto en el mercado de trabajo agrícola como en el urbano.

\section{LOS COSTES DE REPRODUCCIÓN DE LAS UFC}

Cruzando diferentes tipos de documentación (padrones de habitantes y documentación de origen fiscal), hemos elaborado una muestra compuesta por 92 UFC, que agrupan a un conjunto de 523 personas, que tienen en común el hecho de cultivar menos de 5 hectáreas de tierra. Conociendo el sexo y la edad de cada uno de los miembros de las UFC que constituyen nuestra muestra, podemos obtener un valor monetario aproximado que exprese el coste de reproducción de dichas familias. Los gastos de reproducción de una explotación campesina pueden desagregarse en las siguientes partidas ${ }^{17}$ : el consumo doméstico, los gastos de producción de la explotación y las detracciones ${ }^{18}$. A la hora de evaluar los ingresos potencialmente obtenibles se han asignado valores mone-

14 Pech (1975) y Gavignaud (1983).

is Garrier (1975).

16 Morilla (1989) y Pellejero (1990).

17 Los supuestos teóricos en que se basan los argumentos desarrollados en este apartado pueden consultarse en Colomé, Saguer y Vicedo (1996). En el caso especifico de las zonas viticolas también puede consultarse Colomé (1996).

${ }^{18}$ A estas partidas deberiamos añadir otra que bajo el epígrafe de «gastos sociales» agrupase el coste de la dote para las hijas, los costes notariales de transmisión de patrimonio, 
tarios a la producción obtenida según los diferentes aprovechamientos agrícolas. Estos valores monetarios dependen de diferentes variables, como, por ejemplo, el grado de integración del mercado, que puede condicionar el coste del consumo y el nivel de autoconsumo de las explotaciones campesinas; el grado de especialización agraria de la zona estudiada; las características estructurales de la explotación agraria, que pueden condicionar el desarrollo y complejidad de las técnicas utilizadas y, también, las características de la renta y la fiscalidad así como el mercado del crédito.

Aplicando los valores estimados en la tabla 1 a la muestra de 92 UFC que trabajamos, comprobamos cómo estas pequeñas explotaciones agrarias difícilmente podían garantizar su reproducción a partir del producto bruto vinícola obtenido en sus parcelas. Tan sólo tres de estas UFC obtendrían un producto bruto capaz de asumir los costes de reproducción ${ }^{19}$. Pero lo que realmente llama la atención es que cerca de la mitad de las UFC estudiadas disponían de un producto bruto que no les permitía cubrir más del 20 por 100 del consumo doméstico. Estas UFC obtenían parte de los recursos necesarios para su reproducción de los pequeños huertos que cultivaban, de los animales de corral y del cerdo que acostumbraban a criar. Pero en muchos casos, la producción interna de la explotación agraria no bastaba para garantizar la reproducción de las UFC, especialmente en aquellos años en que la producción disminuía por causas climáticas o por alguna plaga.

Esta situación obligaría a las UFC con explotaciones inferirores a 5 hectáreas a intentar acceder al mercado de trabajo para obtener la renta que necesitaban para garantizar su reproducción, dependiendo de la capacidad de cada UFC de exportar trabajo al exterior de la propia explotación. En este sentido, la obtención de unos valores mínimamente representativos del trabajo necesario para la explotación de una hectárea de viñedo permite establecer la superficie vitícola que una UFC podría llegar a trabajar a lo largo del ciclo familiar. Para ello necesitamos, en primer lugar, establecer un modelo de unidad familiar y, en segundo lugar, unos coeficientes de trabajo para cada uno de los miembros de dicha familia. Respecto al primer

los gastos que conporta el culto religioso, etc. La imposibilidad de asignar un valor monetario a esta partida nos impide tenerla en cuenta.

${ }^{17}$ Uno de estos casos corresponde a una explotación agraria con poco más de 5 hectáreas, mientras que en los otros dos casos el saldo positivo se debería al bajo coste de las partidas destinadas a alimentación y vestido, ya que se trata de UFC que cuentan únicamente con dos activos. 


\section{TABLA 1}

\section{Valores monetarios asignados a los gastos de reproducción de una UFC $y$ al producto bruto obtenido por hectárea de tierra}

\begin{tabular}{cc}
\hline Partida & Pesetas/año \\
\hline
\end{tabular}

1. Gastos de reproducción:

1.1. Consumo doméstico:

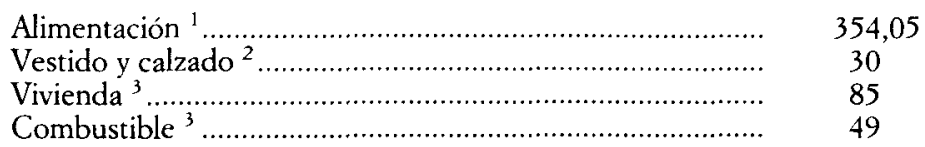

1.2. Explotación:

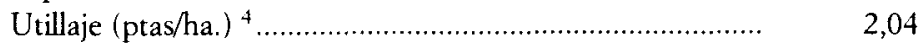

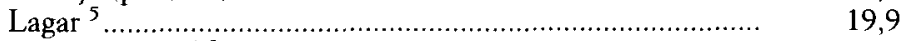

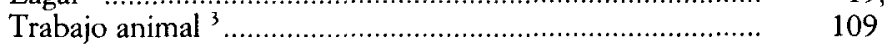

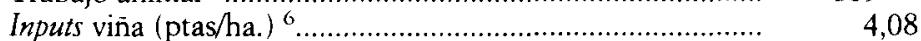

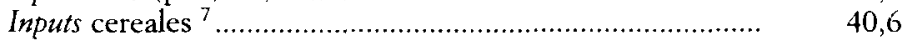

\subsection{Detracciones:}

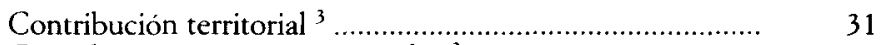

Contribuciones no proporcionales ${ }^{3}$.................................. 21

2. Producto bruto:

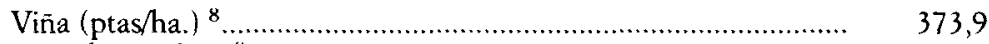

Cereal (ptas/ha.) ${ }^{8}$.......................................................... 362

1 El valor asignado al coste anual de la alimentación corresponde a un activo masculino adulto. Para la composición de la dieta sobre la que se ha calculado este valor, Colomé (1996), pp. 360-372.

2 El valor asignado al coste anual de la partida correspondiente a vestido y calzado también se refiere a un activo masculino adulto. Colomé (1996), pp. 372-374.

3 Colomé, Saguer y Vicedo (1996), p. 95.

4 Colomé (1996), pp. 327-335.

5 Coste de mantenimiento del lagar de una explotación de menos de 5 ha. de viñedo. Colomé (1996), pp. 335-337.

6 Se ha calculado sobre el valor de los productos anticriptogámicos necesarios para combatir el oidium en 1 ha. de viña. En la mayor parte de las cartillas evaluatorias no se contempla este trabajo, por lo que aquí se ha adoptado los valores correspondientes al municipio de La Granada, cercano a Sant Sadurní d'Anoia, para el an̄o 1861. Arxiu Municipal de La Granada, cartilla evaluatoria.

7 Se ha calculado sobre el valor de la simiente necesaria para plantar 1 ha. de cereal, con una producción de 17,86 cuarteras/ha. y unos rendimientos equivalentes a 1:7,63 cuarteras/ha. Colomé (1996), pp. 328-330.

8 En el caso de la vina el producto bruto se ha calculado monetarizando la producción de vino, sarmientos y orujo. La producción estimada por hectárea es de 16,38 cargas de vino. Debido a las fuertes oscilaciones en el volumen total de producción por causas edafológicas, técnicas y climáticas, por ejemplo, se ha optado por calcular una producción media a partir de los datos que poseemos sobre Sant Sadurní d'Anoia en la primera mitad de la década de los años sesenta. El precio del vino se ha calculado a partir de la media de las cotizaciones que alcanzó el vino negro entre 1860 y 1865 en el mercado de Sant Pere de Ribes. Los valores obtenidos a partir de estas fuentes documentales son: producción de vino, 348 ptas./ha.; sarmientos, 17,26 ptas./ha., y brisa, 8,63 ptas./ha. (J. Colomé, 1996, pp. 347-349). Para los cereales se ha calculado a partir del valor del grano y de la paja. Colomé (1996), pp. 346-351. Para las tierras cedidas a rabassa morta se ha estimado que el rabasser satisfacía un censo equivalente a $1 / 3$ del producto bruto obtenido en la explotación. 
punto, en la zona estudiada predominaban las familias de tipo simple, siendo las más comunes aquellas que contaban con cuatro miembros. A pesar de los riesgos que comportan las excesivas simplificaciones, como hipótesis de trabajo podemos establecer que el ciclo de dicha unidad familiar podría resumirse en tres grandes etapas: en la primera de ellas, el núcleo familiar estaría formado por una pareja cuyas edades oscilarían entre los veinte y los treinta años, con dos hijos menores de seis años. En una segunda etapa, los cuatro miembros de la unidad familiar habrian llegado a la plena edad productiva, entre los catorce y los cincuenta años. Finalmente, en la última etapa del ciclo familiar, la UFC estaría formada por la pareja inicial, que habría superado los sesenta y cuatro años y dos activos que se mantendrían entre los veinte y los cincuenta años (los dos hijos o un matrimonio joven) ${ }^{20}$.

\section{TABLA 2}

Modelo de ciclo evolutivo de una familia de tipo simple con cuatro miembros (edades de los miembros de la UFC)

\begin{tabular}{|c|c|c|c|}
\hline & Etapa 1 & Etapa 2 & Etapa 3 \\
\hline 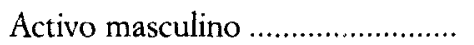 & $20-30$ & $30-50$ & $>59$ \\
\hline 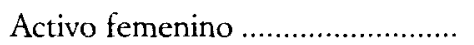 & $20-30$ & $30-50$ & $>59$ \\
\hline 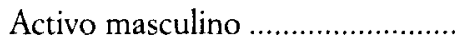 & $00-06$ & $14-30$ & $20-50$ \\
\hline 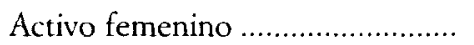 & $00-06$ & $14-30$ & $20-50$ \\
\hline
\end{tabular}

Colomé (1996), p. 331.

Más conflictivo, aún, puede resultar establecer unos coeficientes de trabajo para cada uno de los miembros de la UFC a lo largo de su ciclo evolutivo. De todas formas, no resulta arriesgado suponer que el trabajo vitícola, generalmente, correría a cargo de los activos masculinos de las UFC. El trabajo femenino desarrollado en el interior de la explotación vitícola se orientaría a las actividades vinculadas con la reproducción y el consumo, obteniendo ingresos, en caso de necesidad, con actividades

20) En Cataluna, la vigencia de la figura jurídica del bereu comportaba que generalmente el hijo mayor y su esposa residiesen en el hogar paterno. Una buena sintesis sobre la figura del bereu y el papel que ha jugado en el mundo rural catalán puede consultarse en Terradas (1980 y 1982), Simón Tarrés (1987) y Barrera (1990). Sobre los aspectos juridicos puede consultarse Generalitat de Catalunya (1985). 
complementarias, como, por ejemplo, vendiendo leña o los frutos del huerto y del corral en el mercado o, en momentos puntuales, participando de forma más activa en la explotación de la tierra. La disponibilidad de trabajo masculino, los factores culturales que determinaban el papel que las mujeres jugaban en el seno de las UFC y la versatilidad que caracteriza la actividad de dichas mujeres, nos lleva a aceptar como válido para las actividades femeninas vinculadas al trabajo directo sobre la tierra, el coeficiente propuesto en su momento por Josep Llovet, que equivale al 60 por 100 del coeficiente asignado a los activos masculinos ${ }^{21}$. En el caso de la población menor de catorce años, cabe suponer que los activos masculinos, especialmente entre los siete y los trece años, participarían de forma puntual en algunas de las actividades vitícolas, iniciando de esta forma el período de aprendizaje ${ }^{22}$, mientras que el trabajo en la viña de los activos femeninos menores de catorce sería prácticamente nulo, ya que en esta etapa se produciría el aprendizaje de los roles culturalmente asignados a las mujeres. Los activos masculinos, una vez superados los cincuenta y nueve años, disminuirían su actividad vitícola, produciéndose un cambio generacional en el que dichos activos tendirian a ser sustituidos en la dirección del cultivo por otros activos masculinos más jóvenes. En el caso de las mujeres, una vez superados los cincuenta y nueve años, podemos suponer que su actividad vitícola sería prácticamente nula. A partir de estos argumentos, los coeficientes de trabajo sobre la tierra que utilizamos pueden resumirse en la siguiente tabla:

\section{TABLA 3}

Coeficientes representativos de la participación en la actividad viticola

\begin{tabular}{ccc}
\hline Edad & Activos masculinos & Activos femeninos \\
\hline$<7$ & 0 & 0 \\
$07-13$ & 0,15 & 0 \\
14.59 & 1 & 0,6 \\
$>59$ & 0,5 & 0 \\
\hline
\end{tabular}

Colomé (1996), p. 402.

21 Llovet (1937).

22 En este sentido, cuando hablamos de aprendizaje nos referimos a la transmisión intergeneracional de los conocimientos, que permitía a los jóvenes integrarse paulatinamente en la vida colectiva. Thompson (1995), p. 20. 
Si aceptamos como válidos estos coeficientes, podemos estimar que una UFC en su ciclo inicial podría llegar a cultivar unas 6 hectáreas de viñedo, mientras que en el momento de máxima disponibilidad de trabajo la superficie cultivada podría llegar a las 18 hectáreas (tabla 4).

\section{TABLA 4}

Superficie óptima que una UFC de tipo simple con cuatro miembros podria llegar a cultivar en las diferentes etapas de su ciclo evolutivo

\begin{tabular}{|c|c|c|c|}
\hline Etapas del ciclo familiar 1 & $\begin{array}{l}\text { Jornales diarios } \\
\text { disponibles }\end{array}$ & $\begin{array}{l}\text { Jornales disponibles } \\
\text { a lo largo del año }{ }^{2}\end{array}$ & $\begin{array}{l}\text { Superficie óptima } \\
\text { de viñedo cultivable } \\
\text { por la UFC (ha. })^{3}\end{array}$ \\
\hline 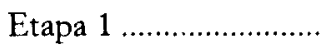 & 1,06 & 304,2 & 6,07 \\
\hline 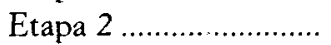 & 3,2 & 918,4 & 18,32 \\
\hline 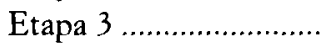 & 2,1 & 602,7 & 12,02 \\
\hline
\end{tabular}

1 Ver tabla 2.

2 Los jornales anuales masculinos posibles para el cultivo de la superficie viticola se han calculado a partir de los días trabajados anualmente en el municipio de Gelida (Alt Penedés) en 1875. En este municipio, aparte de los 47 domingos anuales, tampoco se solía trabajar en Carnaval (cuatro días), Primera Pascua (dos días), Segunda Pascua (dos días), Precepto de Cuaresma (dos días), Navidad (cinco dias), Sant Jordi, Sant Antoni (mes de enero), Sant Antoni (mes de junio), Sant Roc, Sant Camil, Sant Isidre, Santa Llúcia, Todos los Santos (dos días), Fiesta Mayor (cuatro dias), Sant Josep. Sumando los domingos y los días de fiesta tenemos que por regla general un activo masculino solía trabajar unos 287 días al año. Debemos tener presente que estos 287 días equivalen al máximo de jornadas que solían llegar a trabajar. En otras zonas, los valores abtenidos resultan sensiblemente inferiores. Así, G. Postel-Vinay (1994, p. 110) indica que en la Francia de 1860 los trabajadores agricolas tendrian una ocupación anual equivalente a 224 dias. Por otro lado, el número de jornadas trabajadas a lo largo del año puede estar condicionado por prácticas culturales que desconocemos, como, por ejemplo, las ferias y fiestas de los municipios vecinos. Fuente documental: Arxiu Municipal de Gelida, «Llibreta resum de faltes d'assistència», registro 02.03-2,

3 A la hora de calcular el trabajo necesario para cultivar una hectárea de viñedo se han utilizado diferentes cartillas evaluatorias correspondientes a la cornarca del Alt Penedés (La Granada, 1860; Sant Sadurni d'Anoia, 1861; Santa Margarida i els Monjos, 1869) y Anoia (Capellades, 1879; Pujalt, 1888), así como la información correspondiente a la explotación de la familia Raventós de Sant Sadurní d'Anoia (1861). A partir de esta documentación se ha estimado que a lo largo del año agrícola serian necesarios 50,1 jornales de trabajo para la explotación de 1 ha. de viñedo, desagregados en las siguientes partidas: 4 jornales para abonar la tierra con la práctica de los formiguers; 15,7 para el trabajo sobre la tierra (arar y cavar); 14,4 para trabajar las cepas (reponer cepas, podar, esporgar y espampolar); 4,1 jornales para aplicar los productos anticriptogámicos; 11,9 para vendimiar (vendirnia, transporte de las uvas y posterior trabajo en el lagar). 
Teniendo en cuenta que en las zonas vitícolas, entre el 60 y el 80 por 100 de las explotaciones tenían menos de 5 hectáreas, cabe suponer que en un contexto caracterizado por un elevado grado de concentración de la propiedad de la tierra, la mayoría de las pequeñas explotaciones vitícolas estaban en disposición de exportar una cantidad importante de jornales a lo largo del año.

\section{LAS RENTAS SALARIALES}

Ante la capacidad de exportar trabajo que disponían las explotaciones vitícolas con menos de 5 hectáreas, las rentas salariales que podían obtener en el exterior de la explotación eran un factor determinante en sus estrategias de reproducción. El volumen máximo de ingresos salariales que podrían obtener vendría determinado por factores externos (las características económicas de cada zona) e internos a la propia UFC (la superficie de tierra cultivada, el tipo de familia y la estructura por edades). En este último sentido cabe suponer que las familias múltiples acostumbrarían a disponer de un mayor número de activos agrícolas, tanto masculinos como femeninos, de manera que las rentas salariales jugarían un papel más destacado en su proceso de reproducción. Un caso diferente sería el de las familias de tipo simple, puesto que sus rentas salariales vendrían determinadas por el número de hijos $\mathrm{y}$, muy especialmente, por la edad de éstos, ya que no sería hasta los catorce o quince años en que se incorporarían definitivamente en el mercado de trabajo.

El volumen de ingresos salariales óptimos que una UFC podía llegar a obtener se hallaba también estrechamente vinculado al ciclo familiar. Así, el volumen de ingresos salariales tendría a aumentar a medida que los hijos se integrasen en el mercado de trabajo, llegando a una situación óptima cuando la edad del cabeza de familia se situaba entre los cincuenta y sesenta años. A partir de este momento, en la última etapa del ciclo familiar, el envejecimiento del cabeza de familia y el acceso al matrimonio y creación de un nuevo hogar por parte de algunos de los hijos comportaría un retroceso en la capacidad de obtener ingresos complementarios. En este marco, las UFC habrían adoptado diferentes estrategias para mantener el nivel de ingresos, como, por ejemplo, integrar nuevos activos a través del matrimonio de alguno de los hijos. De esta manera, disponían de más fuerza de trabajo y, por lo tanto, podían trabajar una superficie mayor de tierra. Al mismo tiempo, la integración de nuevos activos también per- 
mitía aumentar las posibilidades de obtener nuevas rentas salariales. Una estrategia parecida sería la seguida por las UFC de tipo extenso, donde el mantenimiento de familiares viejos permitía liberar una mayor actividad de los activos femeninos más jóvenes, tanto en el exterior de la explotación como en el propio trabajo vitícola.

Como ya advertíamos anteriormente, las posibilidades de aumentar el ingreso bruto familiar también vendrían condicionadas por factores exógenos a la propia explotación. En este sentido debemos tener en cuenta, en primer lugar, las características económicas de la zona estudiada (tipos de cultivo predominante, mayor o menor grado de especialización agraria e importancia de la producción manufacturera). En segundo lugar, las posibilidades de aumentar el ingreso bruto familiar a través de la obtención de rentas salariales vendrían condicionadas por el nivel técnico alcanzado en la explotación agraria. Finalmente, la reproducción de la UFC vendría determinada por las caracteristicas del mercado de trabajo predominante en el espacio agrario estudiado, prestando especial atención al papel desarrollado por los activos femeninos.

\section{EL MERCADO DE TRABAJO AGRARIO EN LAS ZONAS VITÍCOLAS CATALANAS}

\section{Población activa agraria masculina y trabajo vitícola}

Calculando un valor representativo para los jornales necesarios para trabajar 1 hectárea de viñedo en la Cataluña de la segunda mitad del siglo XIX, podemos estudiar la relación existente entre la capacidad óptima de trabajo de los activos agrícolas masculinos y la demanda anual de trabajo vitícola. Para ello nos servimos de una muestra compuesta por 25 municipios pertenecientes a tres comarcas diferentes (Alt Penedés, Anoia y Bages), con un denominador común: en cada uno de estos municipios la superficie agrícola plantada de cepas equivalía a más del 75 por 100 de la superficie cultivada total, representando en conjunto cerca de 23.000 hectáreas de viñedos. A partir de esta muestra, en la tabla 5 relacionamos el óptimo de trabajo que podían desarrollar los activos agrícolas masculinos de cada municipio con el trabajo que anualmente demandaban las viñas, comprobando cómo a lo largo del año se producía un elevado excedente de trabajo vitícola masculino. Esta capacidad de 


\section{TABLA 5}

Activos agricolas masculinos y demanda actual de trabajo vitícola

\begin{tabular}{|c|c|c|c|c|c|}
\hline Población & $\begin{array}{c}\text { Poblacion } \\
\text { activa agraria } \\
\text { masculina }^{1}\end{array}$ & $\begin{array}{c}H a . \\
\text { viña }^{2}\end{array}$ & $\begin{array}{c}\text { Jomales } \\
\text { anuales } \\
\text { necesarios cultivo } \\
\text { superf. viticola }{ }^{3}\end{array}$ & $\begin{array}{c}\text { Jornales anuales } \\
\text { masculinos } \\
\text { disponibles } \\
\text { cultivo superf. } \\
\text { viticola }\end{array}$ & $\begin{array}{c}\text { Excedente anual } \\
\text { de jomales } \\
\text { agricolas } \\
\text { masculinos }\end{array}$ \\
\hline \multicolumn{6}{|l|}{ Comarca del Alt Penedés: } \\
\hline Cabanyes, Les.............. & 97 & 63,13 & 3.162 & 27.839 & 24.677 \\
\hline Font-rubín....................... & 572 & $1.563,87$ & 78.349 & 164.164 & 85.815 \\
\hline Lavit ............................. & 247 & 286,43 & 14.350 & 70.889 & 56.539 \\
\hline Pacs ............................. & 89 & 354,90 & 17.780 & 25.543 & 7.763 \\
\hline Pla del Penedés ........... & 314 & 385,26 & 19.301 & 90.118 & 70.817 \\
\hline St. Marti Sarroca ........ & 519 & $1.567,12$ & 78.512 & 148.953 & 70.441 \\
\hline St. Pere de Riudebitlles & 345 & 329,33 & 16.499 & 99.015 & 82.516 \\
\hline St. Quintí de Mediona & 450 & 860,97 & 43.134 & 129.150 & 86.016 \\
\hline St. Sadurní d'Anoia .... & 614 & $1.296,26$ & 64.942 & 176.218 & 111.276 \\
\hline Subirats.......................... & 822 & $2.061,46$ & 103.279 & 235.914 & 132.635 \\
\hline Terrassola ........................... & 114 & 647,81 & 32.455 & 32.718 & 263 \\
\hline Total Alt Penedés....... & 4.183 & $9.416,54$ & 471.763 & 1.200 .521 & 728.758 \\
\hline \multicolumn{6}{|l|}{ Comarca de l'Anoia: } \\
\hline 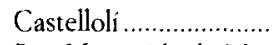 & 198 & 495,29 & 24.814 & 56.826 & 32.012 \\
\hline Sta. Margarida de M. & 186 & 556,90 & 27.900 & 53.382 & 25.482 \\
\hline Odena & 423 & $1.719,01$ & 86.122 & 121.401 & 35.279 \\
\hline Vilanova del Camí ...... & 237 & 461,54 & 23.123 & 68.019 & 44.896 \\
\hline La Pobla de Claramunt & 311 & $1.156,65$ & 57.948 & 89.257 & 31.309 \\
\hline 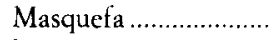 & 355 & $1.224,73$ & 61.358 & 101.885 & 40.527 \\
\hline 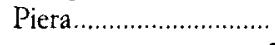 & 1.021 & $2.853,45$ & 142.957 & 293.027 & 150.070 \\
\hline Total Anoia .... & 2.731 & $8.467,57$ & 424.225 & 783.797 & 359.572 \\
\hline \multicolumn{6}{|l|}{ Comarca del Bages: } \\
\hline 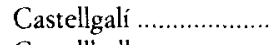 & 258 & 690,08 & 34.573 & 74.046 & 39.473 \\
\hline Castellbell ..................... & 247 & 552,50 & 27.680 & 70.889 & 43.209 \\
\hline Mura ............................... & 204 & 366,01 & 18.337 & 58.548 & 40.211 \\
\hline Rocafort ............................ & 324 & 646,42 & 32.385 & 92.988 & 60.603 \\
\hline Sallent & 672 & $1.374,24$ & 68.849 & 192.864 & 124.015 \\
\hline St. Salvador de G. ....... & 259 & 972,86 & 48.740 & 74.333 & 25.593 \\
\hline St. Vicenç de Castellet & 172 & 371,93 & 18.633 & 49.364 & 30.731 \\
\hline Total Bages.... & 2.136 & $4.974,04$ & 249.199 & 613.032 & 363.833 \\
\hline
\end{tabular}

1 La fuente documental utilizada para obtener la población activa agraria masculina ha sido R. Roig i Armengol (1890).

2 Para la comarca del Alt Penedés, J. Colomé (1996); para la del Anoia, F. Valls (1996), y para el Bages, Ll. Ferrer (1987).

3 Calculado a partir de 50,1 jornales de trabajo por hectárea (ver tabla 4 ).

4 Ver tabla 4. 
trabajo se desviaba hacia otras actividades productivas: la mayor parte de las explotaciones vitícolas poseían pequeñas extensiones de cultivos herbáceos, destinadas a proveer de alimentos tanto a la propia familia como a los animales de tiro. En segundo lugar, las UFC solían trabajar un pequeño huerto con la finalidad de disminuir el gasto destinado a la propia alimentación. Finalmente, la explotación agrícola requería de una serie de trabajos de mantenimiento, tanto de la casa como de los caminos o terrazas, que absorbían parte del trabajo disponible. A pesar de estas actividades, el volumen de trabajo sobrante es de tal magnitud que, con toda seguridad, la mayor parte de las UFC que cultivaban pequeñas explotaciones vitícolas tenían la posibilidad de completar sus ingresos a través de la pluriactividad masculina.

El principal mercado de trabajo para los activos masculinos procedía de la demanda puntual de mano de obra en las explotaciones de más de 10 hectáreas, básicamente de las grandes heredades. Estos propietarios cedían parte de sus tierras bajo el contrato de rabassa morta, pero en las viñas cultivadas de forma directa se incorporaba trabajo asalariado para realizar actividades como la poda, la preparación de formiguers ${ }^{23}$ para abonar o la vendimia, por ejemplo. Esta mano de obra, en el caso de los grandes hacendados, solía proceder de las UFC de rabassers establecidos en sus tierras. De esta forma, los grandes propietarios ejercían un estricto control sobre estas UFC: por un lado, parte de sus posibilidades de reproducción podían depender del acceso a los jornales que les ofrecían los propietarios de la tierra. En segundo lugar, éstos también podían presionar a los rabassers y/o jornaleros a través de préstamos monetarios o en especies (les podía abastecer de productos alimenticios como la sal o el bacalao o de inputs como el azufre o las semillas) ${ }^{24}$, a cargo de los jornales que en un determinado momento pudiese requerir. Finalmente, los propietarios podian controlar el acceso a las tierras de huerta y, también, el acceso a la vivienda.

${ }^{23}$ La fertilización del suelo en las zonas vitícola generalmente quedaba limitada a la práctica de los formiguers, donde se aprovechaba la materia de origen vegetal procedente de la misma viña y la hojarasca de zonas forestales integradas en la misma explotación, o de los bosques sobre los que la comunidad disfrutaba de algún derecho de usufructo. A través de este procedimiento se reducía la compactación de los suelos arcillosos, acelerándose el proceso de mineralización de la materia orgánica y se satisfacía la elevada demanda de potasio que requiere la viña. El recurso a los formiguers comportaba una elevada inversión del factor trabajo, por lo que su práctica no podia realizarse de forma anual y dependia de las características del suelo y de la explotación agraria.

${ }^{24}$ Archivo patrimonial de la familia Raventós, documentación años 1780-1849, documento núm. 9 . 
A pesar del excedente anual de trabajo perteneciente a los activos agrarios masculinos, si analizamos la disponibilidad estacional de trabajo durante la vendimia, comprobamos cómo en la mayor parte de los municipios (tabla 6) existía un déficit importante de mano de obra. Este déficit podía cubrirse con migraciones temporales intracomarcales, especialmente con activos agrícolas procedentes de los principales núcleos urbanos de cada comarca ${ }^{25}$ y con trabajadores fabriles que se encontraban al final del paro estacional dictado por la escasez de agua en los cursos fluviales durante los meses de estío. En segundo lugar, la demanda de mano de obra durante la vendimia solía cubrirse con la llegada de trabajadores procedentes de zonas donde se diese una estacionalidad del trabajo agrícola complementaria con la viña. Finalmente, durante los períodos en que aumentaba la demanda de trabajo vitícola, también lo hacía la participación de los diferentes miembros de la UFC, especialmente de los activos agricolas femeninos.

\section{TABLA 6}

Activos agrícolas masculinos y demanda de trabajo durante la vendimia

\begin{tabular}{|c|c|c|c|c|c|}
\hline Población & $\begin{array}{l}\text { Población } \\
\text { activa agraria } \\
\text { masculina }\end{array}$ & $\begin{array}{l}\text { Ha. } \\
\text { vina }\end{array}$ & $\begin{array}{c}\text { Jornales agricolas } \\
\text { necesarios } \\
\text { durante } \\
\text { la vendimia }\end{array}$ & $\begin{array}{c}\text { Jomales agriculas } \\
\text { masculinos } \\
\text { disponibles } \\
\text { durante } \\
\text { la vendimia }\end{array}$ & $\begin{array}{c}\text { Excedente } \\
\text { o déficit de } \\
\text { jornales agricolas } \\
\text { masculinos duran- } \\
\text { te la vendimia }\end{array}$ \\
\hline \multicolumn{6}{|c|}{ Comarca del Alt Penedés: } \\
\hline Cabanyes, Les............ & 97 & 63,1 & 750 & 1.940 & 1.190 \\
\hline Font-rubi ...................... & 572 & $1.563,9$ & 18.610 & 11.440 & -7.170 \\
\hline Lavit ............................ & 247 & 286,4 & 3.403 & 4.940 & 1.537 \\
\hline 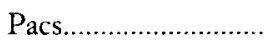 & 89 & 354,9 & 4.223 & 1.780 & -2.443 \\
\hline Pla del Penedés........ & 314 & 385,3 & 4.581 & 6.280 & 1.699 \\
\hline St. Martí Sarroca ....... & 519 & $1.567,1$ & 18.647 & 10.380 & -8.267 \\
\hline $\begin{array}{l}\text { St. Pere de Riudebit- } \\
\text { lles }\end{array}$ & 345 & 329,3 & 3.915 & 6.900 & 2.985 \\
\hline St. Quintí de Medio- & 450 & $\begin{array}{r}861,0 \\
12963\end{array}$ & $\begin{array}{l}10.245 \\
15.425\end{array}$ & $\begin{array}{r}9.000 \\
12.280\end{array}$ & $\begin{array}{l}-1.245 \\
-3.145\end{array}$ \\
\hline $\begin{array}{l}\text { St. Sadurni d'Anoia.. } \\
{ }^{25} \text { En la comarca } \\
\text { censados a finales de } \\
\text { Si desarrollamos las m } \\
\text { un importante excede } \\
\text { déficits detectados er } \\
\text { Manresa. Roig i Arme }\end{array}$ & $\begin{array}{l}\quad 614 \\
\text { a del Bages, } \\
\text { el siglo XIX } 1 \\
\text { mismas opera } \\
\text { lente de mar } \\
\text { en su binterl } \\
\text { engol }(1890)\end{array}$ & $\begin{array}{l}\text { por ejemp } \\
45 \text { trabaj } \\
\text { ciones real } \\
\text { de obra } \\
\text { zd. Sobre }\end{array}$ & $\begin{array}{l}\text { lo, el principal } \\
\text { adores agrícolas } \\
\text { izadas en la tabl } \\
\text { durante la ven } \\
\text { los activos agra }\end{array}$ & $\begin{array}{l}\text { núcleo urbano } \\
\text { y } 1.513,9 \text { hectá } \\
\text { la } 7 \text {, comprobam } \\
\text { dimia, que podi } \\
\text { arios y la super }\end{array}$ & $\begin{array}{l}\text { (Manresa) tenia } \\
\text { áreas de vinedo } \\
\text { mos cómo existía } \\
\text { lía completar los } \\
\text { rficie vitícola de }\end{array}$ \\
\hline
\end{tabular}




\begin{tabular}{|c|c|c|c|c|c|}
\hline Poblacion & $\begin{array}{l}\text { Población } \\
\text { activa agraria } \\
\text { masculina }\end{array}$ & $\begin{array}{l}\text { Ha. } \\
\text { viña }\end{array}$ & $\begin{array}{c}\text { Jomales agricolas } \\
\text { necesarios } \\
\text { durante } \\
\text { la vendimia }{ }^{1}\end{array}$ & $\begin{array}{l}\text { Jornales agricolas } \\
\text { masculinos } \\
\text { disponibles } \\
\text { durante } \\
\text { la vendimia }\end{array}$ & $\begin{array}{c}\text { Excedente } \\
\text { o déficit de } \\
\text { jomales agricolas } \\
\text { masculinos duran- } \\
\text { te la vendimia }\end{array}$ \\
\hline Subirats ........................ & 822 & $2.061,5$ & 24.525 & 16.440 & -8.085 \\
\hline Terrassola ....................... & 114 & 647,8 & 7.708 & 2.280 & -5.428 \\
\hline $\begin{array}{c}\text { Total municipios Pe- } \\
\text { nedés .......................... }\end{array}$ & 4.183 & $9.416,5$ & 112.056 & 83.660 & -28.396 \\
\hline \multicolumn{6}{|l|}{ Comarca de l'Anuia: } \\
\hline $\begin{array}{l}\text { Castelloli..................... } \\
\text { Sta. Margarida de }\end{array}$ & 198 & 495,3 & 5.894 & 3.960 & -1.934 \\
\hline Montbui ............... & 186 & 556,9 & 6.627 & 3.720 & -2.907 \\
\hline Òdena & 423 & $1.719,0$ & 20.456 & 8.460 & -11.996 \\
\hline $\begin{array}{l}\text { Vilanova del Caní ... } \\
\text { La Pobla de Clara- }\end{array}$ & 237 & 461,5 & 5.491 & 4.740 & -751 \\
\hline 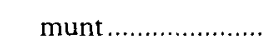 & $31 \mathrm{i}$ & $1.156,7$ & 13.764 & 6.220 & -7.544 \\
\hline Masquefa .................... & 355 & $1.224,7$ & 14.573 & 7.100 & -7.473 \\
\hline Piera............................ & 1.021 & $2.853,5$ & 33.956 & 20.420 & -13.536 \\
\hline Total Anoia .................... & 2.731 & $8.467,6$ & 100.764 & 54.620 & -46.144 \\
\hline \multicolumn{6}{|l|}{ Comarca del Bages: } \\
\hline Casteligali .................... & 258 & 690,1 & 8.212 & 5.160 & -3.052 \\
\hline Castellbell ..................... & 247 & 552,5 & 6.574 & 4.940 & -1.634 \\
\hline Mura ....................... & 204 & 366,0 & 4.355 & 4.080 & -275 \\
\hline Rocafort ........................ & 324 & 646,4 & 7.692 & 6.480 & -1.212 \\
\hline 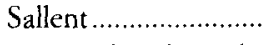 & 672 & $1.374,2$ & 16.352 & 13.440 & -2.912 \\
\hline $\begin{array}{l}\text { St. Salvador de } \\
\text { Guardiola ................. }\end{array}$ & 259 & 972,9 & 11.577 & 5.180 & -6.397 \\
\hline 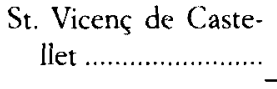 & 172 & 371,9 & 4.4255 & 3.440 & -985 \\
\hline Total Bages................. & 2.136 & $4.974,04$ & 59.191 & 42.720 & -16.471 \\
\hline
\end{tabular}

1 Se han estimado 11,9 jornales de trabajo por hectárea para realizar todo el proceso de vendimia (ver tabla 4).

2 Calculamos que la vendimia se acostumbraba a realizar a lo largo de unos veinte dias. Cuanto más aumenta el número de días, mayores son los riesgos de un accidente climatológico (en las últimas semanas de septiembre acostumbra a granizar algunos dias). Durante este período no se realizaba ningún día de descanso. En este sentido, Manel Raventós indicaba que «ab la nostra mena de treball, no'l podiem interrompre durant la collita, y ab los permisos corresponents, treballàm los tres a quatre dies de festa que bi ha durant ella, fent dir una missa a dos quarts de cinch del mati, per no perdre feyna». Raventós (1911), p. 115 . 


\section{Los activos agrícolas femeninos}

La versatilidad que caracteriza el trabajo de las mujeres en las explotaciones agrarias hace difícil reflejar cuál era su participación real en los trabajos vitícolas. Como ya se ha indicado, la actividad de los activos agrícolas femeninos se centraba, principalmente, en las faenas vinculadas con la reproducción (cría y educación de los hijos), el consumo (mantenimiento del corral, el engorde del cerdo, etc.) y el mantenimiento del hogar. Por otro lado, su participación en el mercado de trabajo vendría determinada por la estructura familiar y por las características económicas de la zona donde residia. Respecto al primer punto, la relación existente entre estruc. tura familiar y actividad femenina en el trabajo agrícola, cabe suponer que el acceso de la mujer al mercado de trabajo sería más frecuente en las familias de tipo extenso, donde el papel que culturalmente se le asignaba en relación a los hijos y el mantenimiento del hogar, podía ser asumido por otros miembros de la UFC con dificultades para realizar los trabajos agrícolas (las mujeres más viejas, por ejemplo). En segundo lugar, su participación activa en el mercado de trabajo vendría determinada por las características económicas de la zona donde residía. Así, como comprobaremos posteriormente, en las comarcas donde existía un cierto tejido industrial, las estrategias familiares se orientaban a completar los ingresos procedentes de los activos agrícolas masculinos con el trabajo fabril de los activos femeninos.

La actividad agrícola femenina también vendría determinada por la estructura de la propiedad y la explotación de la tierra. En este sentido, Maura Palazzi ha demostrado para el caso italiano como un sistema productivo basado en el latifundio, con una oferta rígida de trabajo, tiende a limitar la ocupación femenina de la mayor parte de actividades agrícolas $^{26}$. La misma autora también insiste en destacar la importancia que pueden tener los factores culturales a la hora de limitar las posibilidades de autonomía de los activos femeninos en el mercado de trabajo, señalando que «il forte accentramento della residenza in grandi borghi agricoli e quindi

${ }^{26}$ Hasta el momento, las migraciones temporales agrarias en la Cataluña vitícola no han sido estudiadas. De hecho, tan sólo disponemos de alguna documentación dispersa, como una carta firmada en 1832 por el alcalde de Vilanova i la Geltrú (comarca del Garraf), donde se advertía a diferentes municipios de la comarca del Urgell (Tárrega, Vilagrassa y Anglesola), con una economía de base cerealícola, sobre el día en que se iniciaría la vendimia, con la finalidad de que dichos ayuntamientos advirtiesen «a las personas de ese vecindario que tal vez se determinen a venir a ganar un jornal». Archivo Histórico Municipal de Vilanova i la Geltrú, legajo 2.886. 
la necessità, per recarsi al lavoro, di allontanarsi dalla propia abitazione per tuta giornata e, più spesso, per l'intera settimana o addiritura per periodi più lunghi. Una condizione, questa, incompatibile sia la possibilità per le donne di combinare la cura della casa e della famiglia con il lavoro extradomestico, sia con la esigenza, caracteristica di tuttele società patriarcali, di preservare l'onore della famiglia attraverso il controllo del comportamento sessuale femmenile» ${ }^{27}$.

En las zonas vitícolas catalanas, la participación de los activos femeninos en la explotación de las viñas quedaba circunscrita a los trabajos menos cualificados, como «espampolar», o al momento de máxima demanda estacional de mano de obra: la vendimia. Según los valores obtenidos en la tabla 7 para el municipio de Sant Sadurní d'Anoia (1861), la participación de los activos femeninos quedaría reducida a un 18,4 por 100 sobre el total de trabajo necesario para explotar una hectárea de viña en plena producción. Estos valores son parecidos a los obtenidos en algunos fondos patrimoniales. De esta forma, Josep Raventós, en la explotación de las 57,9 hectáreas de viña que cultivaba de forma directa en 1861, tan sólo contrataba activos femeninos el mes de mayo, para «esporgar» las cepas, y en septiembre, para la vendimia. El primogénito de Josep Raventós, Manel, describió los trabajos realizados por las 200 mujeres que contrataban durante la vendimia, destacando que el primer día eran distribuidas en grupos de vendimiadoras y «triadores», la función de las cuales era la de

\section{TABLA 7}

Jornales femeninos en la explotación de 1 ba. de viña en Sant Sadurni d'Anoia (1861)

\begin{tabular}{|c|c|}
\hline Actividad & Jornales/ba. \\
\hline Espampolar............................ & 5,1 \\
\hline 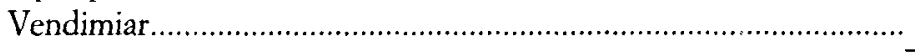 & 4,1 \\
\hline 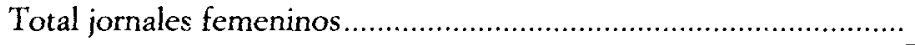 & 9,2 \\
\hline 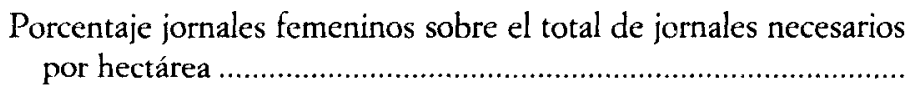 & 18,4 \\
\hline
\end{tabular}

Fuente documental: Archivo de la Cotona de Aragón, sección Hacienda, serie TER, expedientes de reclamaciones.

${ }^{27}$ Palazzi (1994), p. 170. 
separar los granos defectuosos con la finalidad de mejorar la calidad del vino. El principal problema que presentaban estas mujeres, según Manel Raventós, era su elevada movilidad en busca de mejores remuneraciones. Por este motivo se lamentaba del hecho de que «com més adelantada està la collita, succehia anys enrera que si a mitja collita venien pluges, o per podrir-se los rabims en los país s'apujaven los jornals per uns quants dies, o per veura que aqui a casa faltaven pochs dies per collir, y-ls sortía feyna en altre punt, nos deixaven moltes dones com més apurats estavam y se-ns podrian los rabims per no poder-los entrar». Posteriormente añade que normalmente empezaban la vendimia unas 200 mujeres, reduciéndose su número a 150 ó 100 a medida que iban pasando los dias. Con la finalidad de ejercer un mayor control sobre el trabajo femenino, introdujo una gratificación que sólo recibían aquellas mujeres que habían trabajado durante todos los días de la cosecha: «llavors prometerem un premi de un ral més cada día a las que al final de la collita no-ns haguessen faltat un sol dia. Lo remey fóu com posar oli en un llum» ${ }^{28}$.

Finalmente, cabe suponer que la fuerte discriminación sexual que existía en el campo catalán respecto los salarios agrícolas podía determinar la no conveniencia económica para el conjunto de la comunidad que las mujeres entrasen en el mercado de trabajo en competencia con los activos masculinos. Esta misma discriminación sexual podía determinar el espacio que las mujeres ocupaban durante la vendimia. Así, en las pequeñas explotaciones vitícolas la recolección iría a cargo de los activos femeninos de la UFC, mientras que los jornales masculinos disponibles entrarían en el mercado de trabajo para contratarse en explotaciones que demandasen trabajo exógeno ${ }^{29}$.

\section{ACTIVIDAD INDUSTRIAL Y TRABAJO ARTESANAL}

Para algunas UFC, el producto bruto generado en sus pequeñas explotaciones vitícolas y la renta salarial obtenida en las explotaciones vitícolas que puntualmente demandaban trabajo no era suficiente para garantizar su reproducción. En estas ocasiones, la disponibilidad del factor trabajo que caracteriza este tipo de explotaciones les permitía buscar nuevas rentas

${ }^{28}$ Archivo patrimonial de la familia Raventós (Sant Sadurní d'Anoia), volumen documentación años 1860-1869.

${ }^{29}$ Raventós (1911), p. 112. Sobre la evolución de los salarios agrícolas en Cataluña, ver Garrabou, Pujol y Colomé (1991). 
salariales en actividades no agrícolas. Pero ello dependía de las características económicas de las comarcas vitícolas.

A lo largo de la primera mitad del siglo XIX, las actividades manufactureras que se desarrollaban en estas comarcas conocieron un profunda transformación. Esta conversión puede resumirse, básicamente, en cuatro puntos:

1. Práctica desaparición del trabajo a domicilio vinculado al sector textil, especialmente de la lana y el lino.

2. Consolidación de una moderna industria textil en la comarca del Bages.

3. Expansión de la industria papelera en la comarca del Anoia y parte del Penedés.

4. Desarrollo de las actividades artesanales vinculadas al proceso de especialización vitícola.

A fines del siglo xVIII y albores del XIX, el trabajo a domicilio era una importante fuente de recursos en aquellas zonas próximas a los principales centros manufactureros. Así, por ejemplo, en la comarca del Anoia y parte del Alt Penedés, que participaban del binterland de Igualada, una de las principales actividades era la de hilar y tejer lino, cáñamo y lana, siendo los activos agrarios femeninos uno de los principales protagonistas de estas actividades. Pero la estructura económica de estas comarcas experimentó una profunda transformación en la primera mitad del siglo XIX. Esta transformación puede explicarse a partir de dos factores: en primer lugar, la paulatina consolidación de una industria moderna basada en la energía hidráulica de los ríos pirenaico-mediterráneos, en el carbón y el vapor, comportó la localización de la nueva industria en aquellas zonas con cursos fluviales más importantes (el río Llobregat o el Ter, por ejemplo) y en aquellas localidades, como Sant Martí de Provençals o Vilanova i la Geltrú, que poseían un puerto por el que llegaba el algodón y el carbón que demandaba la industria. En segundo lugar, el cultivo de la viña es más intensivo en el factor trabajo y, como ya se ha indicado anteriormente, los activos femeninos podían jugar un papel destacado en el proceso de producción, quedando relegadas otras actividades productivas que anteriormente se desarrollaban en el interior de los hogares. En este sentido, también debe tenerse en cuenta que el desarrolio de actividades manufactureras vinculadas al propio proceso de expansión vitícola habría permitido a los activos agrarios masculinos 
obtener ingresos salariales en el exterior de la explotación agraria, aumentando la participación de las mujeres en el proceso productivo vitícola.

Frente a la crisis que padecían algunos sectores manufactureros tradicionales, otras comarcas vitícolas desarrollaban las nuevas formas de producción industrial. Éste sería el caso del Bages, donde la ventaja comparativa que representaba la disponibilidad de energía hidráulica obtenida gracias al caudal del río Llobregat, permitió el asentamiento de una nueva industria textil, facilitando a los miembros de las UFC la obtención de rentas salariales complementarias. Así, por ejemplo, en el municipio de Navarcles, en el primer tercio del siglo XX, cuando la viña aún ocupaba el 72 por 100 de la superficie agraria, el 65,8 por 100 de los activos masculinos pertenecientes a UFC declaraba como principal ocupación las actividades agrarias, mientras que el 69,1 por 100 de los activos femeninos de los mismos hogares había encontrado trabajo en las fábricas textiles. Paralelamente se consolidaban algunos sectores tradicionales, como la industria papelera en la comarca del Anoia y parte del Alt Penedés. Entre ambas comarcas, a mediados de siglo XIX, agrupaban más del 65 por 100 de las tinas que funcionaban en Catalunya, constituyendo una importante fuente de rentas salariales para las a UFC con pequeñas explotaciones vitícolas. Observemos el caso de Gelida (Alt Penedés). En este municipio, en 1875 , se hallaban censadas 219 familias campesinas $(68,2$ por 100 sobre el total de unidades familiares del municipio), entendiendo como tales aquellas en las que el cabeza de familia declaraba como principal ocupación la de payés. De estas 219 UFC, 145 (el 66,2 por 100) dependían únicamente del producto bruto que obtenían en sus explotaciones para garantizar su reproducción, mientras que en las 79 restantes la reproducción del núcleo familiar era posible gracias a los ingresos procedentes de actividades no agrícolas, de entre las cuales destaca, tal como observamos en la tabla 8 , la ocupación en el sector papelero.

Finalmente, los activos masculinos de las UFC con pequeñaas explotaciones vitícolas solían obtener rentas salariales en aquellas actividades que se habían desarrollado paralelamente con el proceso de especialización vitícola. Éste sería el caso de los toneleros: en Vilafranca del Penedés residían 14 toneleros a fines del siglo XvIII ${ }^{30}$, mientras que en 1876 lo hacían

30 Jaume Torras ya advirtió en su momento que el proceso de expansión vitícola comportaba la creación de ocupación «directamente en la elaboración y envasado de vinos y aguar- 
TABLA 8

Actividades no agricolas declaradas por miembros de las UFC de Gelida (1875)

\begin{tabular}{|c|c|c|c|}
\hline Actividad & Núm. activos & Actividad & Num activos \\
\hline Sirvienta................. & 40 & Tendero ........... & 2 \\
\hline Ind. papelera........................... & 32 & 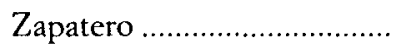 & 2 \\
\hline Carretero ................................ & 6 & 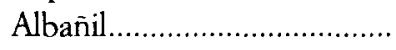 & 1 \\
\hline 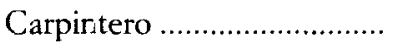 & 3 & Alguacil .......... & 1 \\
\hline Herrero ................................ & 3 & 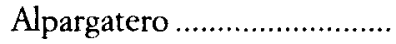 & 1 \\
\hline 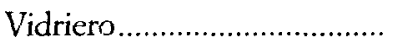 & 3 & 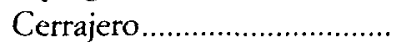 & 1 \\
\hline Dependiente comercio ........ & 2 & Esterero ................................ & 1 \\
\hline Ladrillero ............................. & 2 & 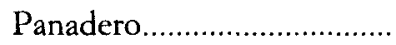 & 1 \\
\hline 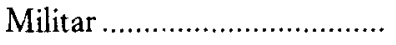 & 2 & 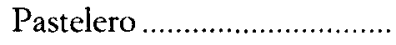 & 1 \\
\hline 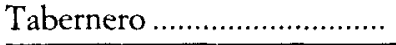 & 2 & 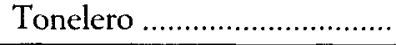 & 1 \\
\hline
\end{tabular}

Fuente documental: Arxiu Historic Municipal de Gelida, Padrón de habitantes de 1875.

59, de los cuales cerca de la mitad pertenecían a UFC ${ }^{31}$. Algo parecido pasaba con los carreteros, que pasaron de los tres censados en 1803 en este municipio a los 15 que constaban en $1876^{32}$.

Pero la pluriactividad que caracteriza las relaciones entre actividades urbanas y agrarias en las zonas vitícolas catalanas debe estudiarse en una doble dirección: de la misma forma que, como ya hemos constatado anteriormente, los activos de las UFC podían obtener ingresos complementarios en las actividades manufactureras y urbanas, también constatamos que toneleros, alpargateros, carreteros y albañiles, entre otros, aparecen como titulares de pequeñas explotaciones vitícolas. En este sentido, si nos remitimos a la muestra de 92 UFC que ya hemos utilizado anteriormente, comprobamos cómo los cabezas de familia que declaraban como principal actividad un trabajo urbano representan el 40,6 por 100 de los titulares de explotaciones que contaban únicamente con tierras en propiedad, el 22,2 por 100 de la explotaciones mixtas (tierras en propiedad y a rabassa morta) y el 27,4 por 100 de las explotaciones a rabassa.

dientes, y también indirectamente, por la correlativa intensificación del transporte y de los inter. cambios». Torras (1984), p. 116.

${ }^{31}$ Colomé, Sabaté y Soler (ed.) (1991), p. 69.

${ }^{32}$ Archivo Histórico Comarcal de Vilafranca del Penédes, Censo de Población de 1876. 


\section{TABLA 9}

Profesión declarada por el cabeza de familia de 92 pequeñas explotaciones viticolas en el municipio de Sant Sadumí d'Anoia (1865)

\begin{tabular}{|c|c|c|c|}
\hline Tipo explotación agraria & Campesinos & $\begin{array}{c}\text { Actividades } \\
\text { urbanas }\end{array}$ & Total \\
\hline Explotación con tierras en propiedad................ & 19 & 13 & 32 \\
\hline $\begin{array}{l}\text { Explotación mixta (tierras en propiedad y a } \\
\text { rabassa) }\end{array}$ & 7 & 2 & 9 \\
\hline Explotación a rabassa morta ............................... & 37 & 14 & 51 \\
\hline 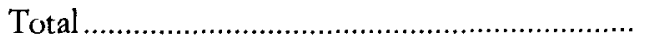 & 63 & 29 & 92 \\
\hline
\end{tabular}

Fuente documental: Archiu Històric Municipal de Sant Sadurní d'Anoia, padrón de habitantes de 1867 .

\section{CONCLUSIONES: PEQUEÑA EXPLOTACIÓN VITÍCOLA Y PLURLACTIVIDAD}

A lo largo de estas páginas hemos intentado realizar una reflexión sobre el papel jugado por las pequeñas explotaciones agrarias como factor determinante en la estructura económica de las comarcas vitícolas catalanas del siglo XIX. La línea argumental seguida se centra en el estudio de las estrategias de reproducción de las UFC que cultivaban pequeñas explotaciones vitícolas. Para ello hemos escogido una muestra de 92 UFC que cultivaban explotaciones vitícolas con menos de 5 hectáreas, y de las que conocemos su composición (edad y sexo de todos sus miembros), la superficie de tierra que poseían y su aprovechamiento agrario. A partir de estas informaciones se han calculado valores monetarios aproximados para las partidas correspondientes a los gastos de reproducción y al producto bruto de las tierras que trabajaban. Los resultados obtenidos apuntan a que las UFC que poseían menos de 5 hectáreas de tierra cultivada difícilmente podían garantizar su supervivencia como unidades productivas con el producto obtenido de las tierras que poseían. Su reproducción sólo era posible a partir de la obtención de rentas salariales en el exterior de la explotación vitícola. En este caso, el principal mercado de trabajo procedía de la demanda de mano de obra generada por las explotaciones más importantes o por la misma estacionalidad vitícola, con sus puntas en los meses de enero, febrero, mayo y septiembre. La segunda fuente de ingresos salariales mas- 
culinos procedía de las actividades que generaba la manufactura y las actividades urbanas. En el caso de las UFC que participaban en este mercado de trabajo, su estrategia consistía en mantener al hijo primogénito (bereu) vinculado a la explotación de la tierra, ayudando al cabeza de familia y adquiriendo experiencia en la gestión del patrimonio familiar, mientras que el trabajo artesanal (tonelería, por ejemplo) o industrial (bodegas, destilerías o la industria papelera, entre otros) quedaba reservado al resto de activos masculinos.

Pero estas posibilidades de obtener ingresos salariales dependian, en buena parte, de los activos femeninos. En las zonas con poco tejido industrial, la actividad de las mujeres solía limitarse a la propia explotación agraria, tanto en el mantenimiento del hogar y cría de los hijos, como participando más activamente en el proceso de producción en los momentos de máxima demanda estacional de mano de obra, especialmente durante la vendimia. En términos generales, su participación en el mercado de trabajo venía determinada por cuatro factores: en primer lugar, la discriminación sexual que se daba en los salarios agrícolas limitaba sus posibilidades de acceder al mercado de trabajo, ya que durante las puntas estacionales de máxima demanda de mano de obra los activos femeninos tendían a participar de forma más intensa en la explotación del viñedo que poseían, sustituyendo a los activos masculinos que buscaban ingresos salariales en el exterior. En segundo lugar, su participación en el mercado de trabajo dependía de la importancia que en cada municipio tenía la industria rural, especialmente textil. También dependían de la tipología familiar y de la regulación del trabajo en el seno de la UFC, de manera que la obtención de rendas salariales por parte de las mujeres sería más corriente en las familias de tipo extenso, donde su papel respecto de los hijos y el mantenimiento del hogar podía ser asumido por otros activos femeninos. Finalmente, a la hora de valorar las posibilidades que tenían de competir en el mercado de trabajo con los activos masculinos, no debemos olvidar factores culturales que relegaban el trabajo femenino a las actividades menos remuneradas.

De esta forma se dibuja un modelo de relaciones sociales y económicas en el que la pequeña propiedad de la tierra jugaría un papel destacado en el proceso de especialización vitícola catalana, convirtiéndose en una reserva de mano de obra para la explotación de las grandes heredades (a través de la cesión de tierras a rabassa morta y del trabajo asalariado), limitando, al mismo tiempo, la emigración de estos activos hacia los nuevos núcleos industriales que se estaban gestando en el siglo XIX. 


\section{BIBLIOGRAFIAA}

ARnABAT, R. (1990): «Notes sobre la conflictivitat senyorial al Penedès (1759-1800)», Estudis d'Història Agrària, núm. 8, pp. 101-122.

Barrera Gonzalez, A. (1990): Casa, berencia y familia en la Cataluña rural, Madrid, Alianza Editorial.

Benach, P. (1911): En defensa de la rabassa morta, Barcelona, Imp. Lit. Arturo Suárez.

Berger, A., y Maurel, F.: Le viticulture et l'économie du Languedoc du Xvir" siècle a nos jours, Montpellier, Les Éditions des Faubourg.

Caminal, E.; Canales, A.; Sola, A., y Torras, J. (1978): «Moviment de l'ingrés senyorial a Catalunya (1770-1835), Recerques, núm. 8, pp. 51-72.

CAÑAS I MAÑE, J. (1907): Explotació del cultiu agrícol, Vilafranca del Penedès, Centre Agricola del Penedés.

Colomé, J. (1990): «Les formes d'accés a la terra a la comarca de l'Alt Penedès: el contracte de rabassa morta i l'expansió vitícola», Estudis d'Història Agrària, núm. 8, pp. 123-144.

- (1996): L'especialització vitícola a la Catalunya del segle XIX. La comarca del Penedès, tesis doctoral, Universitat de Barcelona.

Colomé, J.; SABATE, A., y SOLER, R. (eds.) (1991): El corregiment i partit de Vilafranca del Penedès a l'últim terç del segle XVIII. Respostes al Qüestionari de Francisco de Zamora de Manuel Barba $i$ Roca, Sant Sadurní d'Anoia, Museo de Vilafranca.

Colomé, J., y VALLS, F. (1994): «La viticultura catalana durant la primera meitat del segle XIX. Notes per a una reflexió», Recerques, núm. 30, pp. 47-68.

Colomé, J.; SAguer, E.; Vicedo, E. (1996): «Las condiciones de reproducción económica de las unidades familiares campesinas en Cataluña a mediados del siglo XIX. Una propuesta metodológica», Actas del VIII Congreso de Historia Agraria, Salamanca, pp. 91-106.

Coтs, A. (1984): «Aproximació al estudi dels conflictes senyorials a Catalunya (1751-1808), Estudis d'Història Agrària, núm. 4, pp. 241-268.

Duran i Cañameras, F. (1932): El problema agrario en Cataluña (la cuestión de la rabassa morta), Barcelona.

Durán I Pujol, M. (1985): «L'evolució de l'ingrés senyorial a Catalunya (1500-1799)», Recerques, núm. 17, pp. 7-42.

Ferrer Alòs, Ll. (1987): Pagesos, rabassaires $i$ industrials a la Catalunya central (segles XVIII-XIX), Barcelona, Abadía de Montserrat.

- (1991): «La pequeña explotación en un viñedo de la Cataluña central en los siglos XIX y XX. Consideraciones sobre su evolución y comportamiento», en P. SaAvedra y R. Villares (ed.), Señores y campesinos en la Peninsula Ibérica, siglos XVIII-XX, vol. II, pp. 34-62, Barcelona, Crítica.

- (1994): «Notas sobre la familia y el trabajo de la mujer en la Cataluña central, siglos XviI-XX», Boletín de la Asociación de Demografía Histórica, XII, núm. 2-3, pp. $201-232$.

Fontana, J. (1980): «Crisi camperola i revolta carlina», Recerques, núm. 10, pp. 7-16.

FRADERA, J. M. a (1987): Indústria i mercat. Les bases comercials de la indústria catalana moderna (1814-1845), Barcelona, Crítica. 
García, A., y Soler, R. (1997): «La formación de un centro industrial textil en Cataluña. Vilanova i la Geltrú durante la primera etapa de la revolución industrial», VI Congreso de la Asociación de Historia Económica, IX sesión especializada: la riqueza de las regiones, Girona, pp. 173-187.

Garrabou, R.; Pujol, J., y Colome, J. (1991): «Salaris, ús i explotació de la força de treball agrícola (Catalunya, 1818-1936)», en Recerques, núm. 24, pp. 23-52.

Garrabou, R.; Pujol, J.; Colomé, J., y Saguer, E. (1992): «Estabilidad y cambio de la explotación campesina (Cataluña, ss. XXX-XX)», en R. GARRABOU (coord.), Propiedad y explotación campesina en la España contemporánea, Madrid, pp. 15-92, Madrid, Ministerio de Agricultura, Pesca y Alimentación.

Gavignaud, G. (1983): «Propietaris viticultors al Rosselló», Estudis d'Història Agrària, núm. 6, pp. 7-55.

Generalitat de Catalunya (1985): Compilació del dret civil de Catalunya, Barcelona, Generalitat de Catalunya.

Giménez GuIted, F. (1862): Guía fabril e industrial de España, Barcelona, Libr. del Plus Ultra.

GirALT, E. (1982): «La propietat i l'explotació de la terra durant el segle XIX», en Història econòmica de la Catalunya contemporània. 2. S. XIX. Població $i$ agricultura, Barcelona, Enciclopèdia catalana.

Girona, P. J.; Bodx, J. M. ${ }^{a}$, y JANSANA, A. (1923): La rabassa morta. Informe al Instituto de Reformas Saciales y Memoria, Barcelona, Instituto Agrícola Catalán de San Isidro.

GUTIERREZ, M. (1994): «Tradición y cambio tecnológico: la industria papelera española, 1750-1936», en J. NADAL y J. CATALAN (eds.), La cara oculta de la industrialización española. La modernización de los sectores no lideres (siglos XIX y XX), pp. 341-368, Madrid, Alianza.

Llovet Mont-Ros, J. (1937): «Apunts d'economia agrícola», en Butlletí del Departament d'Agricultura, núm. 4, Generalitat de Catalunya.

Massanell, A. (1988): De la Vilafranca del 1803, Sant Sadurní d'Anoia, Institut d'Estudis Penedenses.

Moreno, B. (1995): La contractació agrària a l'Alt Penedès durant el segle XVIII. El contracte de rabassa morta $i$ l'expansió de la vinya, Barcelona, Fundació Noguera.

Morulla, J. (1989): «Cambios en la viticultura de Andalucía oriental durante la crisis de finales del siglo XIX. Estudio sobre los datos de los informes consulares británicos», Revista de Historia Económica, núm. 1, pp. 157-193.

Muñoz, F. (1990): Creixement demográfic, mortalitat i nupciclitat al Penedès. Segles XVII-YIX, tesis doctoral, Universitat Autònoma de Barcelona.

NADAL, J. (1983): «La població agrària al segle XviI», en Història de Catalunya, vol. 4, pp. 257-272, Barcelona, Salvat.

Nadal, J., y MaluQuer, J. (1985): Catalunya la fábrica d'Espanya, 1833-1936, Barcelona, Ajuntament de Barcelona.

Nadal, J., y TAfunell, X. (1992): Sant Marti de Provençals, pulmó industrial de Barcelona (1847-1992), Barcelona, Columna.

PALAzZI, M. (1994): «Rotture di equilibri tradizionali nella relazioni fra i sessi. I nuovi ruoli familiari e lavorativi delle donne contadine durante la crisi agraria», Instituto «Alcide Cervi». Annali 1992-1993, pp. 197-203. 
PECH, R. (1975): Entreprise viticole et capitalisme en Languedoc-Roussillon. Du philloxéra aux crises de mévente, Toulouse, Le Mirail.

Pellejero, C. (1990): La filoxera en Málaga. Una crisis del capitalismo agrario andaluz, Málaga, Ed. Arguval.

Postel-Vinay, G. (1994): «La desintegració dels mercats de treball a la França del segle XIX», Recerques, núm. 29, pp. 109-127.

RAventós y DOMĖNech, M. (1911): La verema, Libr. de Alvar Verdaguer.

RoIG y ARMengol, M. (1890): Memoria acompañatoria al mapa regional vinicola de la provincia de Barcelona, Barcelona, Establecimiento Tipográfico la Academia.

SANTAmaria, V. (1878): La rabassa morta y el deshaucio aplicado a la misma, Barcelona, Establecimiento Tipográfico de Alfonso Bassas.

- (1894): El contrato de aparcería. Sobre plantaciones de viñas según el artículo 1.656 del Código Civil, Madrid, Libr. Fernando Fé.

Simón Tarrés, A. (1987): «La familia catalana en el Antiguo Régimen», en VVAA, La familia en la España mediterránea (siglos XV-XIX), pp. 65-93, Barcelona, Crítica.

SOLER, R. (1995): Desenvolupament comercial y creixement industrial a Catalunya. Vilanova i la Geltrú, 1839-1914, trabajo de investigación del doctorado interuniversitario en Historia Económica, Universitat Autònoma de BarcelonaUniversitat de Barcelona.

Terradas I SABORIT, I. (1980): «Els origens de la institució de l'hereu a Catalunya», en Quaderns de l'ICA, núm. 1, pp. 65-98.

- (1982): El món bistòric de les masies, Barcelona, Curial.

Thompson, E. P. (1995): Costumbres en común, Barcelona, Crítica.

Torras Elías, J. (1976): Liberalismo y rebeldía campesina, 1820-1823, Barcelona, Ariel.

- (1984): «Especialización agrícola e industria rural en Cataluña en el siglo xviI», Revista de Historia Económica, núm. 3.

VAlls, F. (1996): La dinàmica del canvi agrari a la Catalunya interior. L'Anoia, 1720-1860, Barcelona, Abadía de Montserrat.

-- (1997): «Contractació a rabassa morta i conjuntura vitícola a Catalunya, 1720-1850», Estudis Historics: Documents de l'Arxiu de Protocols, núm. 15, pp. 299.334.

VILAR, P. (1985): Catalunya dins l'Espanya moderna, vol 3, Les transformacions agràries del segle XVIII catala, Barcelona, Edicions GZ (3.a ed.). 